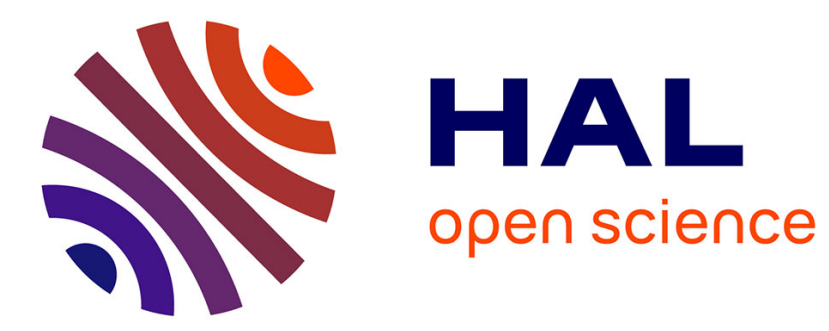

\title{
Evidence of low land surface thermal infrared emissivity in the presence of dry vegetation
}

\author{
Albert Olioso, G. Soria, J. Sobrino, Benoît Duchemin
}

\section{To cite this version:}

Albert Olioso, G. Soria, J. Sobrino, Benoît Duchemin. Evidence of low land surface thermal infrared emissivity in the presence of dry vegetation. IEEE Geoscience and Remote Sensing Letters, 2007, 4 (1), pp.112-116. 10.1109/LRGS.2006.885857 . ird-00389431

\section{HAL Id: ird-00389431 https://hal.ird.fr/ird-00389431}

Submitted on 28 May 2009

HAL is a multi-disciplinary open access archive for the deposit and dissemination of scientific research documents, whether they are published or not. The documents may come from teaching and research institutions in France or abroad, or from public or private research centers.
L'archive ouverte pluridisciplinaire HAL, est destinée au dépôt et à la diffusion de documents scientifiques de niveau recherche, publiés ou non, émanant des établissements d'enseignement et de recherche français ou étrangers, des laboratoires publics ou privés. 


\title{
Evidence of Low Land Surface Thermal Infrared Emissivity in the Presence of Dry Vegetation
}

\author{
Albert Olioso, Guillem Sòria, José Sobrino, and Benoit Duchemin
}

\begin{abstract}
Land surface emissivity in the thermal infrared usually increases when the vegetation amount increases, reaching values that are larger than 0.98. During an experiment in Morocco over dry barley crops, it was found that emissivity may be significantly lower than 0.98 at full cover and that in some situations, it might decrease with increasing amount of vegetation, which was unexpected. Older data acquired in Barrax, Spain, over senescent barley also exhibited emissivity values lower than 0.98 . The decrease of emissivity was also observed by means of simulations done with our land surface emissivity model developed earlier. The main reason for such behavior might be found in low leaf emissivity due to leaf dryness. This letter also stresses that knowledge on leaf and canopy emissivities and on their variation as a function of water content is still very limited.
\end{abstract}

Index Terms-Barley, emissivity, normalized difference vegetation index (NDVI), plant canopy, thermal infrared, wheat.

\section{INTRODUCTION}

$\mathbf{V}$ ARIOUS experimental studies, e.g., [1]-[3], showed that land surface emissivity in the thermal infrared increases with the amount of vegetation, reaching values that are usually larger than 0.98 . This behavior is also in accordance with modeling studies, e.g., [4]-[7]. This has been explained by the internal reflection occurring inside of a plant canopy, constituting a "cavity effect." In the context of Kirchhoff's law, this effect results in an increase of the absorption of thermal radiation by the canopy and then in an increase of emissivity as compared to the emissivity of a single leaf. Simulations by Olioso [6] for a large vegetation amount showed that the cavity effect may increase the emissivity by 0.030 for an erectophile canopy and a leaf emissivity of 0.96 . This effect was lower for more horizontal leaves: 0.026 for a spherical canopy and 0.022 for a planophile canopy. However, the cavity effect is not the only factor required to explain that land surface emissivity, which is a composite of soil and vegetation emissivities, increases when vegetation amount increases: it is also necessary that soil background has lower emissivity than the fully developed canopy. In some situations, it may be possible that land surface

Manuscript received May 9, 2005; revised January 7, 2006. This work was supported by the European Commission through the INCO-MED programs WATERMED (Contract ICA3-CT-1999-00015) and IRRIMED (Contract ICA3-2002-10080).

A. Olioso is with the Institut National de la Recherche Agronomique, Climat, Sol et Environnement, 84914 Avignon, France (e-mail: olioso@ avignon.inra.fr).

G. Sòria and J. Sobrino are with the Department of Thermodynamics, Faculty of Physics, University of Valencia, 46100 Burjassot, Spain.

B. Duchemin is with the Centre d'Etudes Spatiales de la Biosphère, 31401 Toulouse, France, and also with the Faculté des Sciences Semlalia, Marrakech 40000, Morocco.

Digital Object Identifier 10.1109/LGRS.2006.885857 emissivity decreases as vegetation amount increases, e.g., if soil emissivity is very large. This behavior was simulated by Olioso [6] in the case of a soil emissivity of 1.00. As far as we know, no analysis of such behavior was presented in the literature. This letter presents experimental observations of a low value of canopy emissivity and possible decrease in land surface emissivity as the amount of vegetation increases. The reported data were collected over cereal crops in dry conditions near Marrakech, Morocco. They were characterized by low canopy emissivities rather than by large soil surface emissivities. We also found this behavior by reanalyzing measurements obtained over senescent crops in Barrax, Spain, in the frame of previous experiments and by performing radiative transfer simulations for dry-vegetation canopy. The decrease in emissivity may be explained by the dryness of the plant material. The understanding of such behavior is required to better use thermal infrared data in dry conditions (when sensible heat flux may be large) and for a better separation of vegetation and bare surfaces when mapping surface minerals from multispectral thermal radiometers [8], [9].

\section{EXPERIMENTAL DATA}

Land surface emissivity measurements, together with spectral reflectance measurements, were performed in Morocco near Marrakech $\left(31^{\circ} 39^{\prime} \mathrm{N}, 7^{\circ} 37^{\prime} \mathrm{W}\right)$ during spring of 2003 (March 10 and 11). A general description of the experimental conditions was given by [10]. The first set of measurements was performed over wheat by choosing several positions in one field with various amounts of vegetation. This field was irrigated, and the plants were well developed However, some spatial variability occurred because of a nonhomogeneous application of water due to the furrow irrigation system. Each measurement area was carefully chosen in order to provide homogeneous plant and soil conditions over at least $0.5 \mathrm{~m}^{2}$. On the side of this field, few measurements were performed over weeds. The second set of measurements was performed over a barley field. Irrigation over most of this barley field was withdrawn for several weeks, and plants were suffering high water stress. The crop structure was altered. Leaves were flattened. They were still green but presented significant leaf rolling, indicating that strong desiccation had occurred. Some measurements over barley were also performed in areas of the field where plants suffered only moderate water stress (in the following, they will be termed as "wet barley" in opposition to "dry barley" for the stressed areas). Measurements were also performed over bare soil in each field. In both fields, the underlying soil surface was very dry since no irrigation or rain occurred during the previous 
TABLE I

Land Surface Emissivity and NDVi Measured Near Marrakech, Morocco, on March 10-11, 2003. Measurement Standard DeViations Are Presented in Brackets. VAlues for Wheat and Wet Barley Were Obtained From the MEAN of the Three LaRgest MeAsured Values (All of Them at a LARge CANopy Cover). For Dry BARley, the VAlue AT The LARGESt NDVI IS Given

\begin{tabular}{|c|c|c|c|c|c|}
\hline & \multicolumn{4}{|c|}{ Emissivity } & \multirow[t]{2}{*}{ NDVI } \\
\hline & $8-13 \mu \mathrm{m}$ & $11.5-12.5 \mu \mathrm{m}$ & $10.3-11.3 \mu \mathrm{m}$ & $8.2-9.2 \mu \mathrm{m}$ & \\
\hline Wheat at large NDVI & $0.981(+/-0.006)$ & $0.984(+/-0.006)$ & $0.976(+/-0.009)$ & $0.964(+/-0.016)$ & $0.85(+/-0.004)$ \\
\hline Wet Barley & $0.981(+/-0.003)$ & $0.981(+/-0.003)$ & $0.972(+/-0.004)$ & $0.958(+/-0.005)$ & $0.85(+/-0.005)$ \\
\hline Dry Barley & $0.963(+/-0.006)$ & $0.968(+/-0.005)$ & $0.953(+/-0.005)$ & $0.934(+/-0.007)$ & $0.64(+/-0.006)$ \\
\hline Soil in the wheat field & $0.957(+/-0.002)$ & $0.978(+/-0.001)$ & $0.964(+/-0.002)$ & $0.911(+/-0.004)$ & $0.17(+/-0.003)$ \\
\hline Soil in the barley field & $0.958(+/-0.004)$ & $0.980(+/-0.002)$ & $0.965(+/-0.003)$ & $0.923(+/-0.002)$ & $0.29(+/-0.013)$ \\
\hline
\end{tabular}

ten days. Soil texture was similar in both fields: $30 \%$ clay, $27 \%$ sand, and $43 \%$ loam.

Emissivity measurements were carried out with the box method (two-lid version [11], [12]), which was applied in the four channels of a CIMEL 312-1 thermal infrared radiometer (8-13, 11.5-12.5, 10.3-11.3, and 8.2-9.2 $\mu \mathrm{m}$ [13]). The four channels were scanned successively in the same measurement sequence. Rubio et al. [12] showed that the main sources of error when using the box method were related to hot-lid and target changes in temperature during the measurement process (the method assumed that both temperatures did not change). In order to control the risk of error, three repetitions were done at the same position over each measurement area (each of them was $1 / 10 \mathrm{~m}^{2}$ ), and each measurement sequence was taken as short as possible (the hot lid was applied for around $20 \mathrm{~s}$ ). The data were rejected when the measured standard deviation in the $8-13-\mu \mathrm{m}$ band exceeded 0.01 . This corresponded to the expected accuracy of emissivity measurement for further applications such as the retrieval of surface temperature from thermal measurements. The rejection level was usually obtained when the measurement sequence was longer or when the hot-lid temperature was changing faster than usual. No direct control of the evolution of the target temperature was possible; however, it was expected that temperature change was limited since reported values in previous studies ranged from almost zero to less than half a degree [3], [10].

Reflectance measurements were done over the same positions as emissivity measurements. They were performed using a handheld MSR16 multispectral radiometer (Cropscan, Inc., Rochester, MN), which measured both incoming solar irradiance and radiance from the surface over several optical bands. The reflectances in the two bands centered on red (0.63$0.69 \mu \mathrm{m})$ and near infrared $(0.76-0.90 \mu \mathrm{m}), \rho_{\text {red }}$ and $\rho_{\text {nir }}$, respectively, were used to derive the normalized difference vegetation index (NDVI) (the NDVI was computed according to NDVI $\left.=\left(\rho_{\text {nir }}-\rho_{\text {red }}\right) /\left(\rho_{\text {red }}+\rho_{\text {nir }}\right)\right)$. Each measurement was taken by handing the radiometer at $1.4 \mathrm{~m}$ high at nadir. The size of the scanned area was about $0.35 \mathrm{~m}^{2}$ on the ground. Six samples were acquired for each location by rotating the pole that supports the sensor. The standard deviation of these measurements was always very low, which made it possible to assume that each measurement area was homogeneous and that the NDVI measurements may be related to emissivity measurements.

In the following, NDVI will be used as an indication of the amount of vegetation within each type of surface (wet or dry). As a matter of fact, Duchemin et al. [10] derived an accurate relationship between leaf area index and NDVI for wheat. However, it is worth noticing that NDVI cannot be used here for comparing the amount of vegetation between wet crops (wheat and unstressed barley) and dry crops (dry barley) since dry canopy structure was significantly affected by water stress.

\section{EXPERIMENTAL RESULTS}

Emissivities for the two types of crop are presented in Table I and plotted as a function of NDVI in Fig. 1. Emissivity measurements over wheat showed an increase in emissivity in the four channels when the amount of vegetation increased. The values at large vegetation in the four channels were above soil values by $0.024(8-13 \mu \mathrm{m}), 0.006(11.5-12.5 \mu \mathrm{m})$, $0.010(10.3-11.3 \mu \mathrm{m})$, and $0.052(8.2-9.2 \mu \mathrm{m})$. For the barley crop, two different behaviors were observed. Measurements acquired over the "wet" areas presented large NDVI values and emissivity values that were almost similar to the values obtained over the wheat crop. Over the "dry barley" areas, the NDVI values were lower than 0.7 , and the emissivity values were significantly lower than the values obtained over the "wet barley" areas. Moreover, if emissivity was increasing when NDVI increased in the 8-13- and the 8.2-9.2- $\mu \mathrm{m}$ channels, it was actually decreasing in the two other channels. The values obtained over the water-stressed plants were only reaching 0.963, 0.968, 0.953, and 0.934 at an NDVI of 0.64. Between 10.3 and $12.5 \mu \mathrm{m}$, these values were lower than the soil values by 0.012 in both channels. They were above soil values by 0.011 between 8.2 and $9.2 \mu \mathrm{m}$.

\section{Discussion}

In this section, we first analyze the results obtained in Marrakech. During the second time, we present older data, which confirm the Marrakech results, and during the third time, we analyze the possibility of simulating such results by using a radiative transfer model.

The measurements performed over water-stressed barley in Marrakech indicated emissivity values that are significantly lower than the values obtained over watered crops (the difference was between 0.015 and 0.030 , depending on the channel). In the 10.3-12.5- $\mu \mathrm{m}$ range, emissivity was decreasing below soil values. Considering previous experimental results, this behavior was not expected. We must notice that measurements made over dry material using the box method (in particular, the two-lid method) might be less accurate than measurements made over wet material. As a matter of fact, dry material had lower thermal inertia than wet material, and it might 

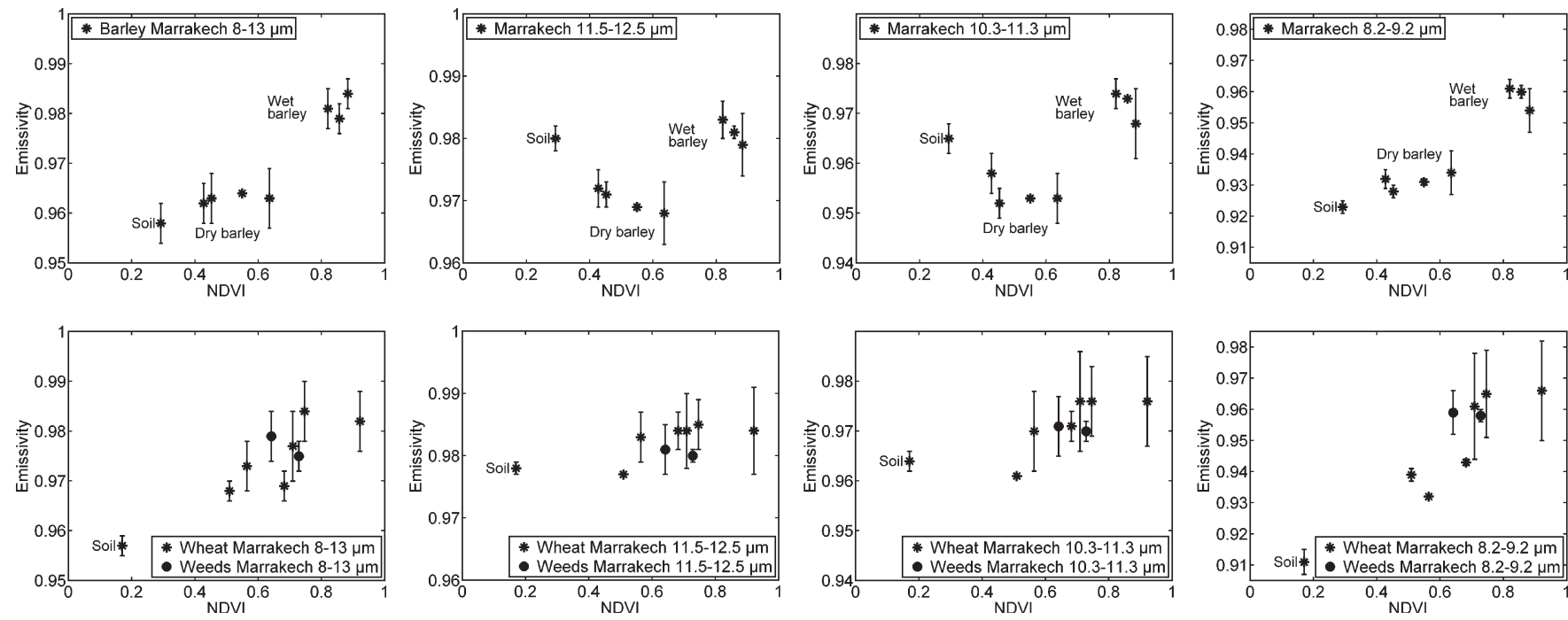

Fig. 1. Emissivity measurements over (top graphs) barley field and (bottom graphs) wheat field in the four channels of the CIMEL 312-1 thermal radiometer in Marrakech (note that NDVI was used to characterize the vegetation amount for each type of canopy (wet barley, dry barley, and wheat), but it cannot be used to compare data from one type of canopy to the other because of changes in canopy structure and leaf properties between wet and dry canopies).

undergo a larger change of target temperature during the time of application of the hot lid, inducing a larger error in the derived emissivity. However, this effect was limited in our case since 1) the impact of soil on thermal inertia was still large as dryvegetation amount was low (NDVI never exceeded 0.65) and 2) thermal inertia of fully wet vegetation is only three times larger than thermal inertia of fully dry vegetation (this estimation was based on information compiled from [14] and [15]; a similar ratio would hold for bare soil). Nevertheless, the last measurement channels in the measurement sequence (8.2$9.2 \mu \mathrm{m}$ and at a lesser extent, 10.3-11.3 $\mu \mathrm{m}$ ) might have been affected. Assuming that in the worst case, the elevation of the target temperature along the sequence was three times the maximum elevation obtained over wet surfaces in previous studies $(0.5 \mathrm{~K})$, i.e., $1.5 \mathrm{~K}$, the underestimation of emissivity for a full cover was lower than 0.011 in the 8.2-9.2- $\mu \mathrm{m}$ channel (increase of $\sim 1.5 \mathrm{~K}$ ), 0.006 in the $10.3-11.3-\mu \mathrm{m}$ channel (increase of $\sim 1 \mathrm{~K}$ ), and 0.003 in the $11.5-12.5-\mu \mathrm{m}$ channel (increase of $\sim 0.5 \mathrm{~K}$ ). If such errors occurred: 1) dry barley emissivity values would still be significantly lower than the values obtained over watered crops in all channels, and 2) differences between land surface emissivities and soil emissivities would be lower. Thus, it would be less obvious that land surface emissivities were lower than soil emissivities between 10.3 and $12.5 \mu \mathrm{m}$ : Differences would be reduced to 0.006 in the $11.5-12.5-\mu \mathrm{m}$ channel and 0.009 in the $10.3-11.3-\mu \mathrm{m}$ channel (considering measurement variability, these differences might not be significant).

In order to confirm our findings, we inspected already published land surface emissivity measurements and data available in various databases. For data acquired in the Barrax area in Spain $\left(39^{\circ} 10^{\prime} \mathrm{N}\right.$ and $\left.3^{\circ} 1^{\prime} \mathrm{W}\right)$ [12], [16]-[18], some low values of emissivity were found over nonirrigated barley fields (V25 and V27 in early June 1999) and over a field covered by barley straw after harvesting (St34 at the end of July 2000). Other data acquired in the same area during the EFEDA campaign in June 1991 [12] were in a similar range or lower (only
8-14- $\mu \mathrm{m}$ large-band values were available). All these data are summarized together with Barrax soil data in Table II. They were obtained in dry conditions over senescing or senesced crops (as shown by NDVI data in Table II), which may be characterized by low vegetation moisture content. Emissivity was lower than soil emissivity between 10.3 and $12.5 \mu \mathrm{m}$ in the case of field V27 (as measurement errors in these channels might be significant, these data must be taken with caution). After the crop harvest, the values obtained over straw in Barrax (St34) were about 0.90-0.91, which are significantly lower than soil values in any channels. Fig. 2, which is redrawn from [19], presents the emissivities of fresh and dry grass sods. Fresh-sod emissivities ranged between 0.97 and 0.99. Dry-sod emissivities varied between 0.90 and 0.925 in the $10.3-12.5-\mu \mathrm{m}$ spectral interval, which was in a close range with the straw measurements in Barrax. In the 8.2-9.2- $\mu \mathrm{m}$ band, the dry-sod emissivities were significantly higher than the straw value. The low sod emissivity values between 10 and $13 \mu$ m may indicate that leaf emissivities were significantly lower than 0.90 in this case. As water has very high absorbing rate in the $8-14-\mu \mathrm{m}$ window, it is expected that dry leaves have significantly lower emissivities than fresh leaves since water usually represents $75 \%-90 \%$ of fresh leaf material. The senescent foliage spectra in [20] presented a leaf reflectance of up to $19 \%$, which may correspond to an emissivity of 0.81 if no radiation was transmitted through the leaf.

For low leaf emissivity values (0.90), Olioso [6] simulated a land surface emissivity of 0.96 at an NDVI of 0.6 for a spherical canopy (the full cavity effect corresponded to an increase of 0.07 for this simulation). In the case of a planophile canopy, the simulated emissivity would have been even lower. This was in agreement with our measurements over barley in Morocco. Fig. 3 presents new simulations performed using the radiative transfer model presented in [6]. In this model, emissivity was computed as the absorption coefficient of directional thermal radiation. Radiative transfer calculations were based on the equations of the SAIL model [21]. The simulations 
TABLE II

Land Surface Emissivity and NDVI in Barrax, Spain. NDVi Data Were Obtained From the Airborne Polder Sensor in BarRaX (Using Only Data at Nadir). Emissivities Were Measured With the BoX Method Using an Everest 210 During EFEDA [12], A RaYTeK MOdel ST6 DuRING DAISEX (8-14- $\mu \mathrm{m}$ BAND) [16], AND Four-BAND CIMEL 312 During DAISEX [16]-[18]. MEASUREMENT Standard DeViations ARE PRESENTED IN BRaCKETS

\begin{tabular}{|c|c|c|c|c|c|c|c|}
\hline & Experiment and reference & & & Emissivity & & & NDVI \\
\hline & & $8-14 \mu \mathrm{m}$ & $8-13 \mu \mathrm{m}$ & $11.5-12.5 \mu \mathrm{m}$ & $10.3-11.3 \mu \mathrm{m}$ & $8.2-9.2 \mu \mathrm{m}$ & \\
\hline Barley & EFEDA (June 1991) [12] & $\begin{array}{c}0.959 \\
(+/-0.011)\end{array}$ & & & & & \\
\hline Barley & EFEDA (June 1991) [12] & $\begin{array}{c}0.965 \\
(+/-0.008)\end{array}$ & & & & & \\
\hline Barley, field V25 & DAISEX (June 1999) [16] & $\begin{array}{c}0.970 \\
(+/-0.005)\end{array}$ & & & & & $\begin{array}{c}0.39 \\
(+/-0.026)\end{array}$ \\
\hline Barley, field V27 & DAISEX (June 1999) [16-18] & & $\begin{array}{c}0.971 \\
(+/-0.006)\end{array}$ & $\begin{array}{c}0.959 \\
(+/-0.012)\end{array}$ & $\begin{array}{c}0.944 \\
(+/-0.013)\end{array}$ & $\begin{array}{c}0.957 \\
(+/-0.007)\end{array}$ & $\begin{array}{c}0.41 \\
(+/-0.066)\end{array}$ \\
\hline Straw of Barley, field St34 & DAISEX (July 2000) $[16,17]$ & & $\begin{array}{c}0.913 \\
(+/-0.016)\end{array}$ & $\begin{array}{c}0.898 \\
(+/-0.006)\end{array}$ & $\begin{array}{c}0.900 \\
(+/-0.009)\end{array}$ & $\begin{array}{c}0.918 \\
(+/-0.006)\end{array}$ & \\
\hline Bare soil, field s3 (=V27) & DAISEX (August 1998) $[16,17]$ & & $\begin{array}{c}0.966 \\
(+/-0.003)\end{array}$ & $\begin{array}{c}0.965 \\
(+/-0.004)\end{array}$ & $\begin{array}{c}0.968 \\
(+/-0.005)\end{array}$ & $\begin{array}{c}0.959 \\
(+/-0.006)\end{array}$ & \\
\hline Bare soil, field s10 & DAISEX (June 1999) [16, 17] & $\begin{array}{c}0.967 \\
(+/-0.015)\end{array}$ & $\begin{array}{c}0.966 \\
(+/-0.003)\end{array}$ & $\begin{array}{c}0.967 \\
(+/-0.005)\end{array}$ & $\begin{array}{c}0.969 \\
(+/-0.002)\end{array}$ & $\begin{array}{c}0.955 \\
(+/-0.005)\end{array}$ & $\begin{array}{c}0.23 \\
(+/-0.027)\end{array}$ \\
\hline
\end{tabular}

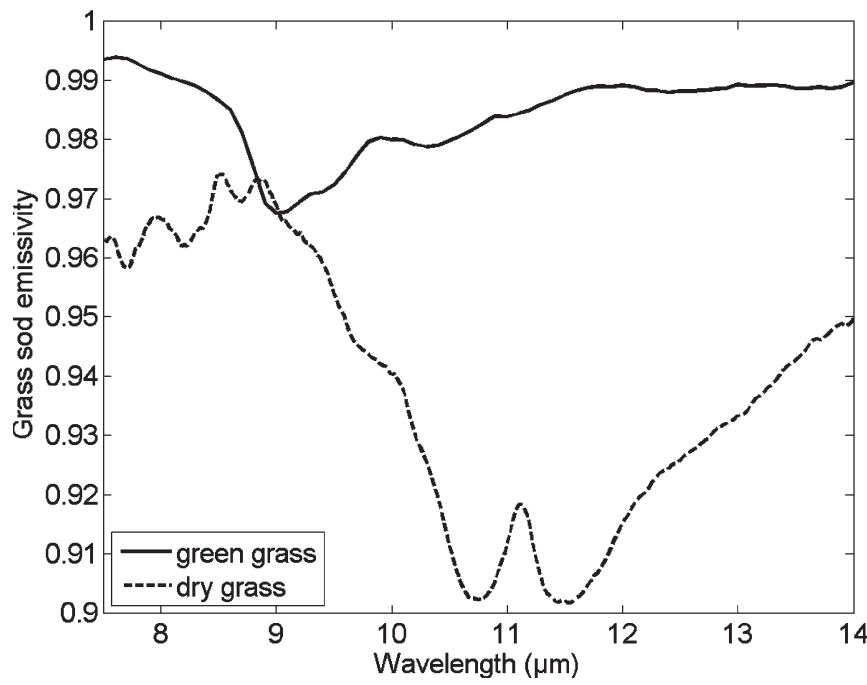

Fig. 2. Emissivity response spectra for dry grass sod and green grass sod redrawn from [19] (originating from the ASTER spectral library).

were performed assuming the following conditions: nadir viewing, planophile canopy, measured soil surface emissivities (dry barley field in Marrakech), and leaf emissivities derived from the senescent foliage ("dry") and the green foliage ("wet") spectra presented in [20, Fig. 9]. As expected from [6], simulations for wet canopies showed an increase of emissivity in every channel when NDVI increased. At a large NDVI, the simulated land surface emissivities were always larger than 0.98, which was in agreement with classical bibliographic information, e.g., [1]-[3], and with the green grass sod spectrum presented in Fig. 2. In the case of dry canopies, large decreases of land surface emissivities were simulated between 10.3 and $12.5 \mu \mathrm{m}$, while an increase was found in the 8.2-9.2- $\mu \mathrm{m}$ band (in which soil value was very low). Simulated values at a large NDVI were in good agreement with the grass sod spectrum presented in Fig. 2. It was interesting to compare the simulations with the experimental data obtained in Marrakech. For wet canopies, the simulations were always higher than the measured values; for dry canopies, the simulations were significantly lower than the measurements in the $8-13-\mu \mathrm{m}$ channel and between 10.3 and

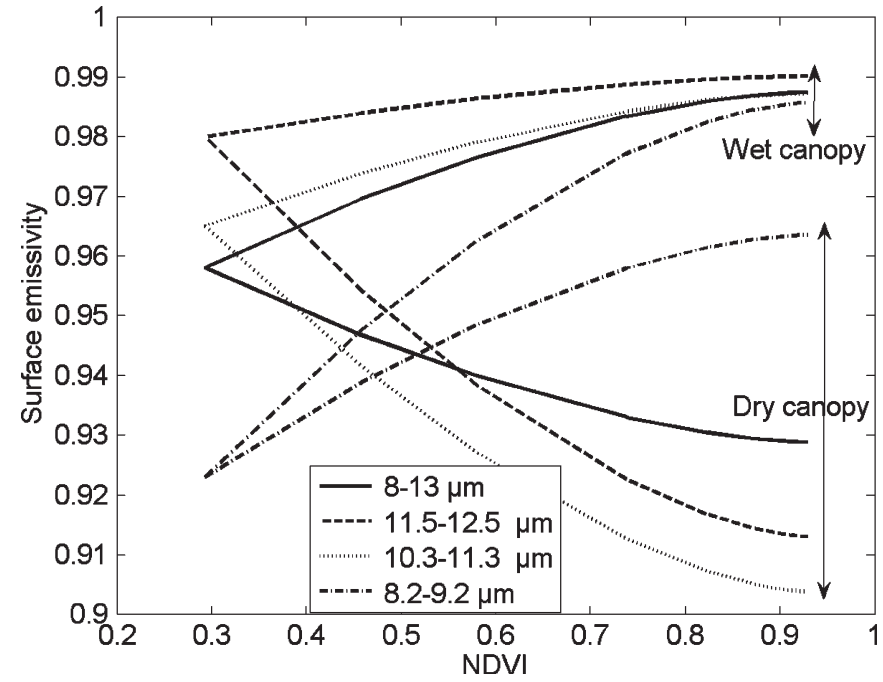

Fig. 3. Simulated (lines) and measured (symbols) emissivities in the four channels of the CIMEL 312-1 thermal radiometer over dry barley in Marrakech. The simulations were performed using the radiative transfer model proposed by Olioso [6].

$12.5 \mu \mathrm{m}$, while they were higher in the 8.2-9.2- $\mu \mathrm{m}$ channel. These behaviors might suggest that the dry barley leaves were wetter than the senescent leaves used for the simulations and that the wet barley leaves and wet wheat leaves were drier than the green leaves used for simulating wet canopies. Actually, it was very difficult to perform a quantitative comparison mainly because knowledge on leaf spectral properties in the thermal infrared was very limited (only very little published data can be found), and no information existed on the variations of leaf emissivities as a function of leaf water content. In a qualitative way, however, the simulation results clearly supported that dry canopies can have low emissivities and that emissivity can decrease when the vegetation amount increases.

\section{Conclusion}

Our results over dry crops and other data obtained over senescent crops and stubble indicate that thermal infrared emissivities between 8 and $13 \mu \mathrm{m}$ can be significantly lower than 
emissivities obtained over well-watered and green vegetation. They also showed that in some situations, dry plants might have lower emissivity than bare soil and that in these cases, land surface emissivity might decrease when the vegetation amount increases (however, the measured accuracy may not be large enough to reach a definitive conclusion on that point). Model results from [6] and from the present letters confirm such behaviors. Low values of emissivity and their possible decrease below soil values can be explained by three factors: 1) the soil emissivity is large and is actually larger than the emissivity of the plant canopy at full cover (it is important to notice that soil emissivity may be large when the soil surface is wet; however, this was not the case in our experiment);2) the plants are dry, implying that the leaf emissivity is low (maybe as low as 0.9 or even 0.8 ); and 3) the plant architecture is modified so that the cavity effect is reduced.

Up to know, detailed knowledge on the effect of drying and senescence on emissivity at the leaf level and at the canopy level is missing. The determination of the respective influences of leaf drying, canopy architecture changes, and soil background effect will require the use of radiative transfer models in leaf and plant canopy, together with specific measurements over dry areas. Such research is currently undergoing at Institut National de la Recherche Agronomique and the University of Valencia.

\section{ACKNOWLEDGMENT}

The authors would like to thank the many people who helped them during the experiment and C. Bacour of LSCE-Saclay for providing the Polder data in Barrax.

\section{REFERENCES}

[1] A. A. van de Griend and M. Owe, "On the relationship between thermal emissivity and the normalized difference vegetation index for natural surfaces," Int. J. Remote Sens., vol. 14, no. 6, pp. 1119-1131, 1993.

[2] E. Valor and V. Caselles, "Mapping land surface emissivity from NDVI: Application to European, African, and South American areas," Remote Sens. Environ., vol. 57, no. 3, pp. 167-184, Sep. 1996.

[3] M. Sugita, T. Hiyama, and T. Ikukawa, "Determination of canopy emissivity: How reliable is it?" Agric. For. Meteorol., vol. 81, no. 3, pp. 229-239, Nov. 1996.

[4] V. Caselles and J. A. Sobrino, "Determination of frosts in orange groves from NOAA-9 AVHRR data," Remote Sens. Environ., vol. 29, no. 2, pp. 135-146, Aug. 1989.

[5] Y. A. Anton and Y. K. Ross, "Emissivity of a vegetation-soil system," Sov. J. Remote Sens., vol. 7, no. 5, pp. 859-869, 1990. (in English translation).
[6] A. Olioso, "Simulating the relationship between thermal emissivity and the normalized difference vegetation index," Int. J. Remote Sens., vol. 16, no. 16 , pp. 3211-3216, 1995.

[7] W. C. Snyder and Z. Wan, "BRDF models to predict spectral reflectance and emissivity in the thermal infrared," IEEE Trans. Geosci. Remote Sens., vol. 36, no. 1, pp. 214-225, Jan. 1998.

[8] R. G. Vaughan, S. J. Hook, W. M. Calvin, and J. V. Taranik, "Surface mineral mapping at Steamboat Springs, Nevada, USA, with multiwavelength thermal infrared images," Remote Sens. Environ., vol. 99, no. $1 / 2$, pp. 140-158, Nov. 2005.

[9] A. Mushkin, L. K. Balick, and A. R. Gillespie, "Extending surface temperature and emissivity retrieval to the mid-infrared (3-5 $\mu \mathrm{m})$ using the Multispectral Thermal Imager (MTI)," Remote Sens. Environ., vol. 98, no. 2/3, pp. 141-151, Oct. 2005.

[10] B. Duchemin, R. Hadria, S. Er-Raki, J. Ezzahar, G. Boulet, P. Maisongrande, A. Chehbouni, R. Escadafal, J. Hoedjes, H. Karroui, S. Khabba, B. Mougenot, A. Olioso, J.-C. Rodriguez, V. Simonneaux, and F. Timouk, "Monitoring wheat phenology and irrigation in Center of Morocco: On the use of relationship between evapotranspiration, crops coefficients, leaf area index and remotelysensed vegetation indices," Agric. Water Manag., vol. 79, no. 1, pp. 1-27, 2006. DOI: 10.1016/j.agwat.2005.02.013.

[11] F. Nerry, J. Labed, and M. P. Stoll, "Spectral properties of land surfaces in the thermal infrared band-Part II: Field method for spectrally averaged emissivity measurements," J. Geophys. Res., vol. 95, no. B5, pp. 7045-7062, 1990.

[12] E. Rubio, V. Casselles, and C. Badenas, "Emissivity measurements of several soils and vegetation types in the $8-14 \mu \mathrm{m}$ waveband: Analysis of two fields methods," Remote Sens. Environ., vol. 59, no. 3, pp. 490-521, Mar. 1997.

[13] M. Sicard, P. R. Spyak, G. Brogniez, M. Legrand, N. K. Abuhassan, C. Pietras, and J.-P. Buis, "Thermal infrared field radiometer for vicarious cross-calibration: Characterization and comparison with other field instruments," Opt. Eng., vol. 38, no. 2, pp. 345-356, Feb. 1999.

[14] D. de Vries, "Thermal properties of soils," in Physics of Plant Environment, W. R. Van Wijik, Ed. Amsterdam, The Netherlands: North Holland, 1963, pp. 210-235.

[15] W. Brutsaert, Evaporation Into the Atmosphere, vol. 299. Dordrecht, The Netherlands: Kluwer, 1982.

[16] DAISEX project home page. [Online]. Available: http://io.uv.es/projects/ daisex/

[17] E. Rubio, V. Caselles, C. Coll, E. Valor, and F. Sospedra, "Thermal infrared emissivities of natural surfaces: Improvements on the experimental set-up and new measurements," Int. J. Remote Sens., vol. 24, no. 24, pp. 5379-5390, Dec. 2003.

[18] J. A. Sobrino, J.-C. Jiménez-Muñoz, J. El Kharraz, M. Gómez, M. Romaguera, and G. Sòria, "Single-channel and two-channel methods for land surface temperature retrieval from DAIS data and its application to the Barrax site," Int. J. Remote Sens., vol. 25, no. 1, pp. 215-230, Jan. 2004.

[19] A. N. French, T. J. Schmugge, and W. P. Kustas, "Discrimination of senescent vegetation using thermal emissivity contrast," Remote Sens. Environ., vol. 74, no. 2, pp. 249-254, Nov. 2000.

[20] J. W. Salisbury and D. M. D'Aria, "Emissivity of terrestrial materials in the 8-14 $\mu$ m atmospheric window," Remote Sens. Environ., vol. 42, no. 2, pp. 83-106, Nov. 1992.

[21] W. Verhoef, "Light scattering by leaf layers with application to canopy reflectance modeling: The SAIL model," Remote Sens. Environ., vol. 16, no. 2, pp. $125-141$, Oct. 1984. 